\title{
CERVANTES Y LA DIVINIZACIÓN LITERARIA (RECONSTRUCCIÓN DE UNA VETA DEL IDEARIO ESTÉTICO CERVANTINO) ${ }^{1}$
}

1. No faltará quien juzgue de antemano ociosa e infructífera toda nueva incursión en el pensamiento estético cervantino, a tenor del copioso y autorizado cúmulo de bibliografía crítica existente sobre aspecto tan capital. Sin embargo, el hecho de intentar este singular asedio desde un ángulo insólito de aproximación, creo que será suficiente para justificar su pertinencia y novedad. Esta original perspectiva que propugno, viene dada por uno de los fenómenos más característicos de la espiritualidad y de la cultura literaria de la España aurisecular: la conversión a un plano de significación religiosa, de los paradigmas del arte profano. La rehabilitación que de esta zona de nuestras letras he llevado a cabo en otro estudio ${ }^{2}$, me persuade a examinar, a esta nueva luz, la producción cervantina, con la mirada, solícita y vigilante, puesta en escrutar cualesquiera rastros, reminiscencias o indicios que acierte a detectar, no importa lo minúsculos que ellos sean con tal que testimonien la reacción de su autor ante hecho tan extendido y significativo de nuestra literatura áurea. En efecto, son varios los lugares, diseminados en el universo de su obra, en que Cervantes se refirió incidentalmente a determinadas parcelas del pujante y omnímodo proceso divinizatorio

1 La presente comunicación compendia algunas cuestiones primordiales tratadas muy por extenso en el estudio que da título a mi libro Cervantes frente a la divinización literaria y otros ensayos, volumen inaugural de la colección de «Ensayos de Literatura Española", que constituye una de las líneas de mi editorial filológica.

2 Francisco Javier SÁnchez Martínez, Historia y crítica de la poesía lírica culta "a lo divino" en la España del Siglo de Oro. Alicante, F. J. Sánchez Martínez-Editor, Ensayos de Literatura Española, 1995-1999, 5 tomos en 6 volúmenes. 
que a la sazón estaba operando sobre la literatura seglar en todos los órdenes. En lo que sigue, a más de hacer acopio y dar cumplida noticia de cuantas alusiones cervantinas a este fenómeno me ha sido dable recabar, procederé, en última instancia, a arracimarlas en un coherente haz testimonial que acredite, no sólo la impronta que tan relevante corriente socioliteraria dejó en el ánimo de Cervantes, sino, muy especialmente, los límites en torno a los cuales fluctuó su actitud crítica respecto a los postulados artísticos y morales en que la práctica divinizadora se funda.

2. Aunque en su mínima expresión, cabe afirmar que, en el conjunto de la obra cervantina, están cabalmente representadas las fundamentales tendencias de la poesía en el siglo XVI sobre las que actuó juntamente la torsión divinizadora: de una parte, la tradición lírica de progenie popular (representada por la zarabanda); de otra, la del italianismo poético aclimatado a nuestra literatura (cuya señera encarnación es Garcilaso de la Vega), y, finalmente, el nuevo arte de hacer romances (tiene la corriente neorromanceril, género de ascendencia tradicional reelaborado desde presupuestos cultos, su exponente, dentro del corpus cervantino, en la celebérrima jácara quevediana de Escarramán).

3. En su pretensión de expugnar el impenetrable reducto de la mansión de Carrizales para gozar de la custodiada Leonora, el Loaysa de El celoso extremeño, sabedor de la desmedida inclinación que a la música muestra el portero eunuco Luis, se brinda, embozado en el disfraz de tullido mendicante, a enseñarle a tañer con su grasienta y mal encordada guitarra un repertorio de tonadas que en aquel momento gozaban de candente boga y actualidad, entre las que se hace expresa mención de «las de la zarabanda a lo divino»:

-Todas ésas [sc. tonadas] son aire - dijo Loaysa- para las que yo os
podría enseñar, porque sé todas las del moro Abindarráez, con las de su
dama Jarifa, y todas las que se cantan de la historia del gran sofí
Tomunibeyo, con las de la zarabanda a lo divino, que son tales que hacen
pasmar a los mismos portugueses; y esto enseño con tales modos y con
tanta facilidad, que aunque no os deis priesa a aprender, apenas habréis
comido tres o cuatro moyos de sal cuando ya os veáis músico corriente y
moliente en todo género de guitarra ${ }^{3}$.

Interesa, ante todo, advertir que la voz zarabanda designaba, en tiempo de Cervantes, una realidad compleja en que se involucran, al par, lo musical, lo coreográfico, lo lírico e, incluso, lo poético en su estricta acepción de paradigma métrico. De cuáles sean las es-

3 Novelas ejemplares, ed. de Harry Sieber. Madrid, Cátedra (Letras Hispánicas, núms. 105 y 106), 2 vols., 9. a edición, 1986-1987, vol. II, p. 110. 
pecíficas facciones que caracterizan la fisonomía de la zarabanda, da idea bastante aproximada un nutrido elenco de documentos coetáneos de signo diverso, que han sido sistemáticamente recopilados y en diacrónico orden dispuestos, en sendos estudios, por Emilio Cotarelo y Mori $^{4}$ y Daniel Devoto ${ }^{5}$. Predominan, en este acervo documental, los juicios execratorios, emitidos desde una óptica moralista, que coinciden en condenar la índole provocativa, lasciva y deshonesta que informa el baile y cantar de la zarabanda - pues de entrambas facetas, como queda dicho, participa ésta-; ni dejaron de promulgarse contra ella edictos de prohibición e interdicción, infructuosamente renovados de tiempo en tiempo, pues su cumplimiento distó mucho de ser efectivo, como así lo acreditan los innúmeros testimonios de su fulminante éxito, que alcanzó incluso a la esfera sacra. Entre las danzas que se ejecutaron en la procesión de las fiestas del Corpus de Sevilla en 1593, consta haber sido una de ellas la de la zarabanda; y, en el capítulo XII de su Tratado contra los juegos públicos, el cual versa, en especial, sobre «el baile y cantar llamado zarabanda», el P. Juan de Mariana declara, por su parte, lo que sigue:

[...] por ahora sólo quiero decir que entre las otras invenciones ha salido estos años un baile y cantar tan lascivo en las palabras, tan feo en los meneos, que basta para pegar fuego aun a las personas muy honestas. Llámanle comúnmente zarabanda [...]. Y ¿qué dirán Dios y todo el mundo cuando sepan que en España, en la cual nos gloriamos, y con mucha razón, que la religión se ha conservado en su puridad y entereza, estas deshonestidades han entrado en los templos consagrados a Dios, y los han mezclado en el culto divino? [...] Sabemos por cierto haberse danzado este baile en una de las más ilustres ciudades de España, en la misma procesión y fiesta del Santísimo Sacramento del Cuerpo de Cristo, Nuestro Señor, dando a su Majestad humo a narices con lo que piensan honralle. Poco es esto: después sabemos que en la mesma ciudad, en diversos monesterios de monjas y en la mesma festividad se hizo, no sólo este son y baile, sino los meneos tan torpes, que fue menester se cubriesen los ojos las personas honestas que allí estaban; ¿que esto es razón que se sufra y disimule y que las casas de Dios y los monesterios se hagan oficinas de deshonestidad, y esto con título de que se honra a Dios en ello y se aumenta el culto divino? ${ }^{6}$.

La injerencia del susodicho cantar y baile tanto en la fiesta sacramental como en las recreaciones conventuales, de que da pun-

${ }_{4}$ Colección de entremeses, loas, bailes, jácaras y mojigangas desde fines del siglo XVI a mediados del XVIII. Madrid, Casa Editorial Bailly-Bailliére (Nueva Biblioteca de Autores Españoles, núms. 17 y 18), 2 vols., 1911, vol. I, pp. cclxv-cclxxi.

5 "La folle sarabande», Revue de Musicologie, XLV, 1960, pp. 8-25.

6 Tratado contra los juegos públicos, en Obras del Padre Juan de Mariana. Tomo II. Madrid, M. Rivadeneyra Impresor-Editor (Biblioteca de Autores Españoles, núm. 31), 1854, p. 433. 
tual noticia el docto jesuita, permite sospechar - sin que ello suponga obviar que, en ocasiones, pudiera incurrirse en manifiestos excesos y desarreglos- un proceso de adaptación o acomodación de la compostura de la zarabanda al carácter sacro y piadoso de tales ambientes. Quien conozca con cierto pormenor a qué extremos extendió su jurisdicción el vendaval divinizador en el paisaje literario de la España áurea, no arredrándose ni aun ante las piezas que, por su carácter impúdico y libidinoso o por su porte rafez y picaresco, prejuzgaríamos las menos a propósito para tan pío intento, no pondrá en el entredicho de la duda el que la apuntada posibilidad llegara a materializarse. El pasaje de la novela cervantina así lo certifica, y no hay razones para desconfiar de su crédito.

Esto no obstante, ha habido razones de orden documental que han llevado a algún crítico a recelar de la existencia, en el Siglo de Oro, de zarabandas «a lo divino», atribuyendo las tales a mera lucubración o entelequia de Cervantes, quien las habría postulado movido de un designio satírico. Ocurre que quienes hasta ahora han sometido a cierta consideración el consabido pasaje cervantesco, no han sido capaces de allegar ejemplar poético alguno que demuestre positivamente la realidad histórica de la zarabanda «a lo divino». Tal es el caso de Francisco Rodríguez Marín, quien, sin dudar un ápice de la veracidad del testimonio de don Miguel, declara, empero, desconocer muestras de tales piezas, aunque afirme que "de seguro las había» ${ }^{7}$. Menos crédulo, Devoto se muestra entre dubitativo y reacio a dar fe a su existencia, aun a pesar del testimonio consignado por Cervantes en su Novela del celoso extremeño. Éstas son sus palabras:

\begin{abstract}
Remarquons bien que, sur l'existence ou la non-existence de "coplas de la zarabanda a lo divino" (et nous verrons plus loin qu'elles sont plutôt difficiles à concevoir), nous ne savons rien: y en eut-il? Peut-être; mais ce qu'il importe de souligner est ceci: notre texte [refiérese el crítico francés al pasaje de El celoso extremeño que aquí trato de elucidar] n'est pas une preuve de leur existence, mais tout le contraire ${ }^{8}$.
\end{abstract}

Para disipar definitivamente las incertidumbres, cautelas y reparos que en sus anotadores y exégetas ha suscitado la referencia cervantina a "la zarabanda a lo divino», voy a exhumar seguidamente un ejemplar que demuestra, con todos los rigores y exigencias de la ciencia positivista, que tampoco este género de obras se sustrajo al universal embate divinizador. Trátanse de unas «coplas en alabança de nuestra señora de la cabeça contrahechas a la

\footnotetext{
${ }^{7}$ En su edición de las Novelas ejemplares cervantinas. Madrid, Espasa-Calpe (Clásicos Castellanos, núms. 27 y 36), 2 vols., 1917, vol. II, pp. 114-115.

8 Art. cit., p. 28.
} 
çarabanda buelto de lo humano a lo diuino", que integran el contenido del pliego suelto poético, impreso en Baeza en 1594, de que es autor Alonso Becerro, "priuado del sentido visiuo» y "vezino de la villa de Aguilar», tal y como se hace constar en el frontispicio. Resulta, por demás, curioso que el título con que, en el interior del opúsculo, figura epigrafiada la pieza que nos concierne, quede antonomásticamente reducido al de "Coplas de la çarabanda a lo diuino", lo que - si paramos, además, mientes en las circunstancias de la data del pliego y su procedencia andaluza - hace presumir muy verosímilmente que bien pudiera ser ésta la misma a que aludía Loaysa. Sea como quiera, he aquí las referidas coplas:

COPLAS DE LA ÇARABANDA A LO DIUINO.

$$
\begin{aligned}
& \text { Afuera çarabanda } \\
& \text { que otra mejor anda }{ }^{9} \text {. } \\
& \text { Alla en sierra morena } \\
& \text { esta vna cabeça buena } \\
& \text { que a todos libra de pena } \\
& \text { y nos pone el alma blanda } \\
& \text { afuera çarabanda } \\
& \text { que otra mejor anda } \\
& \text { Esta virgen de primor } \\
& \text { por librarnos de error } \\
& \text { se le aparecio a vn pastor } \\
& \text { limpia de todo pecado } \\
& \text { o mi Dios sagrado } \\
& \text { como estays llagado. [...]. }
\end{aligned}
$$

Demostrada la fidedignidad del aserto de Cervantes, réstame, por último, apuntar el probable trasfondo de perspicaz ironía que tal vez subyaga a la mención de «las [tonadas] de la zarabanda a lo divino» en el citado episodio de la Novela del celoso extremeño. Esta pulsión irónica cervantina cabría detectarla en lo siguiente: si atendemos al ligamen que vincula, como un cuerpo homogéneo, la zarabanda con el resto de canciones y tonadas connumeradas en dicho pasaje (adscritas, en su mayoría, al romancero morisco), no dejaremos de advertir que se trata, sin excepción, de piezas ungidas por el favor popular en sus estratos más ínfimos y plebeyos (no se olvide que es bajo la apariencia de un astroso mendigo como Loaysa trata de embaucar con semejante oferta musical al ignaro y simple negro, sabiéndolo tocado de la afición mélica; ni caiga en

9 Este estribillo contrahace "a lo divino» el característico de la zarabanda, el cual, según testimonia LUIS BRICEÑo en su Método para aprender a tañer la guitarra a lo español (París, 1626), dice así: «Ándalo, Zarabanda, / que el amor te lo manda». 
saco roto la constatación de ser, muy reveladoramente, la zarabanda "a lo divino» antes exhumada una típica copla de ciegos, impresa en volandero pliego de cordel, destinada a rodar de boca en boca por calles y plazuelas). La celebridad del repertorio con que Loaysa pretende cohechar la voluntad del negro eunuco, lleva, en contrapartida, aneja su despectiva estimación artística por el narrador (vale decir Cervantes), quien ha escogido deliberadamente tales canciones de entre las más arregostadas a lo vulgar, precisamente aquellas que están situadas en los antípodas de su gusto propio, tan embebido de garcilasismo. Si a esta consideración, unimos la del aditamento «a lo divino» con que tilda y apellida a la zarabanda, habremos de ver en ello un gesto o ademán, no exento de significación, que apunta, por añadidura, al desdén que debió sentir el autor de las Ejemplares por la versión «a lo divino» de piezas de baja estofa y vil extracción.

4. Si en el caso precedente nos ha sido posible barruntar efluvios de la sutilísima ironía que informa el arte cervantino en orden a expresar alusivamente, por modo oblicuo, su censura de la práctica divinizatoria de piezas que, sobre ser de ínfimo jaez, inciden resueltamente en lo lúbrico e indecoroso, dicha vena irónica va a campear singular e irrestañablemente en la manera como don Miguel escarnece, en un lugar de su Entremés del rufián viudo llamado Trampagos, el señalado proceso de divinización que por aquellos años afectaba al célebre personaje rufianesco creado por Quevedo en su romance jácaro de la Carta de Escarramán a la Méndez, aquel en que se contiene la adversa fortuna del valiente Escarramán, natural de Sevilla, al cual prendieron por muchos delitos que cometió, y que, después de recorridas las acostumbradas calles, caballero en un borrico, recibiendo una tunda de doscientos azotes, fue condenado a servir en las galeras reales por espacio de diez años. Esta jácara quevedesca, que puede pasar por el más emblemático espécimen de su género, se configura, según queda indicado en su título, como una epístola que dirige el renombrado rufián a su coima la Méndez, refiriéndole, en tono de irónico envanecimiento, los cruentos castigos padecidos por causa de los desafueros perpetrados:

$$
\begin{aligned}
& \text { Ya está metido en la trena } \\
& \text { tu querido Escarramán, } \\
& \text { que estos alfileres vivos } \\
& \text { me prendieron sin pensar. }[\ldots]^{10} \text {. }
\end{aligned}
$$

10 Obra poética. Teatro y Traducciones poéticas, ed. de José Manuel Blecua. Madrid, Castalia, 4 vols., 1969-1981, vol. III, p. 267. 
En conformidad con la evolución típica del género de la jácara, la de Escarramán no tardaría en ser puesta en música, convirtiéndose en baile de moda, pronto incorporado al programa del espectáculo teatral, lo que contribuyó sobremanera a su difusión y popularidad. Es, precisamente, la danza del Escarramán uno de los blancos más frecuentemente asaetados por los impugnadores del teatro áureo en sus virulentas diatribas moralistas, a despecho de las cuales no tardaría en ser divinizada. Ni el sórdido y rufianesco carácter de los ambientes y personajes que pueblan las jácaras, que alcanza asimismo al nivel sociolectal (lenguaje de germanía) en que estaban compuestas, ni sus hilarantes y desenvueltas melodías, ni los ambladores movimientos que contorsionaban lúbricamente el cuerpo de quienes las danzaban, representaron nunca - cada uno de estos factores por sí o todos juntamente- un obstáculo para ser vertidas a un sentido espiritual. El resultado de la divinización del género jacaresco fue un extraño compuesto sacroprofano en que las personas divinas, incluso las más excelsas, eran cantadas con el aire jocoso, lenguaje germanesco y caracterización degradatoria anejos al tratamiento literario de uno de los estratos más abyectos de la sociedad áurea: el de la rufianesca. De ahí que no deba sorprender que una institución como el Santo Oficio - que, en términos generales, se caracterizó por su amplia permisividad en lo tocante a la moda literaria y artística de la divinización de los valores profanosacabara por sentir ciertos recelos cuando tal práctica actuaba sobre productos tan alejados del decoro y gravedad que reclamaba para sí la esfera de lo sagrado. Que las versiones «a lo divino» de la jácara de Escarramán despertaron, en determinadas circunstancias, la vigilancia inquisitorial, lo demuestra un valiosísimo documento de 1663 en que el Tribunal del Santo Oficio de la villa de Madrid registró, a este respecto, que «asimismo se cantan jácaras y el Escarramán, y cuantas seguidillas lascivas se cantan en la comedia, y los arrieros y mozos de mulas por los caminos, reducidos a lo divino, con el mismo aire, quiebros y guturaciones que las canta la mayor lascivia de los representantes».

Así lo atestigua también Cervantes en su Entremés del rufián viudo llamado Trampagos. La imprevista irrupción de Escarramán hacia el final de la pieza (quien regresa del cautiverio in partibus infidelium en que lo habían puesto una serie de avatares acaecidos en el curso del cumplimiento de su condena en las galeras) despierta el unánime asombro del resto de los personajes entremesiles. La luenga ausencia en que Escarramán ha estado, le lleva a inquirir de ellos:

¿Qué se ha dicho de mí en aqueste mundo, en tanto que en el otro me han tenido mis desgracias y gracia? 
lo que va a suscitar un varillaje de respuestas que ilustran las diversas tribulaciones de este personaje en su ulterior fortuna literaria, una de las cuales es, precisamente, la de su divinización: "Hante vuelto divino; ¿qué más quieres?», exclama la Repulida ${ }^{11}$. A este propósito, juzgo plausible descubrir, en la irónica concepción cervantina de la figura de Escarramán en relación con la trama de su entremés, un alusivo trasfondo sacrílego. La repentina aparición -que tiene tanto de súbita y apoteósica apariencia teatral como de paródica agnición - del afamado rufián, ataviado «como cautivo, con una cadena al hombro», ante el coro de sus cofrades y prosélitos de la vida airada, deviene grotesco trasunto de la de Jesucristo a sus apóstoles después de su Resurrección. No creo, a este respecto, que la interjección de sorpresa que profiere la Repulida («¡Jesús!») al ver de improviso irrumpir en escena a Escarramán, esté desprovista de clara intención religiosa, toda vez que éste habíase subrogado en el propio Cristo en las diversas contrafacturas de la jácara de Quevedo. La proximidad, en este parlamento, de los nombres de «Jesús» y «Escarramán» se me antoja, pues, sobremodo reveladora, funcionando como un indicio insidiosamente cifrado por la ironía de Cervantes. El término "visión» contribuye, por su parte, a subrayar el aparatoso efectismo de una aparición que tiene visos de sobrenatural. Sobre la base de todo lo argüido, puede concluirse que, en el marco de inversión de los valores institucionales, que es uno de los signos de identidad del género entremesil, la divinización que la figura de Escarramán había experimentado en los primeros años del siglo XVII, propició, en manos de Cervantes, un especioso juego de alusiones blasfematorias y desacralizadoras, encaminadas a reforzar, mediante la ironía, su posición crítica impugnadora de la práctica divinizadora.

5. Sobradamente conocida es la profunda devoción que Cervantes sintió por Garcilaso de la Vega, de quien su obra está cuajada de innúmeras reminiscencias y citas expresas. Esta rendición de tributo por el alcalaíno al toledano ofrece inusitado interés a nuestro intento, toda vez que permite descubrir, no sin cierto grado de sorpresa, un matiz diferencial en la global animadversión cervantina hacia la práctica divinizadora. 1614 marca un punto de inflexión en la profesión cervantina de garcilasismo, que parece, por vez primera, orientarse hacia la posibilidad efectiva de su aplicación con fines morales y aun abiertamente religiosos. Cervantes pasa a ejercitarse propiamente en la divinización de la poesía del ingenio toledano con motivo de su intervención en la justa literaria, ce-

11 Entremeses, ed. de Nicholas Spadaccini. Madrid, Cátedra (Letras Hispánicas, núm. 162), 1987, 5. a edición, pp. 134-135. 
lebrada en 1614 en los conventos carmelitanos de San Hermenegildo y Santa Ana de Madrid, en alabanza de la beatificación de Teresa de Jesús. En tal ocasión, contrahizo Cervantes unos versos de la Égloga I de Garcilaso, aplicándolos a la glorificación de la mística Doctora. Ello ocurría nueve años después de su categórico pronunciamiento, consignado en el prólogo de la Primera Parte del Quijote (Madrid, 1605), en contra de la mezcla de lo humano con lo divino, tildándola de abominable mixtión «de quien no se ha de revestir ningún cristiano entendimiento». Henos, pues, aquí ante un hecho que no ha sido debidamente ponderado por los cervantistas: el que don Miguel incurriera en una práctica que entraba en franca colisión con los principios y convicciones más firmemente asentados de su ideario moral y estético. Que Cervantes era sabedor del remedo "a lo divino" que en tal sazón ejecutaba, está fuera de toda duda, a juzgar por lo notorio y flagrante del mismo. Basta comparar la estancia inicial de la égloga garcilasiana con su correlativa de la canción cervantina, para percatarse de la lúcida conciencia artística de quien así enajenaba toda una considerable secuencia de versos profanos incorporándolos directamente a su composición sacra:

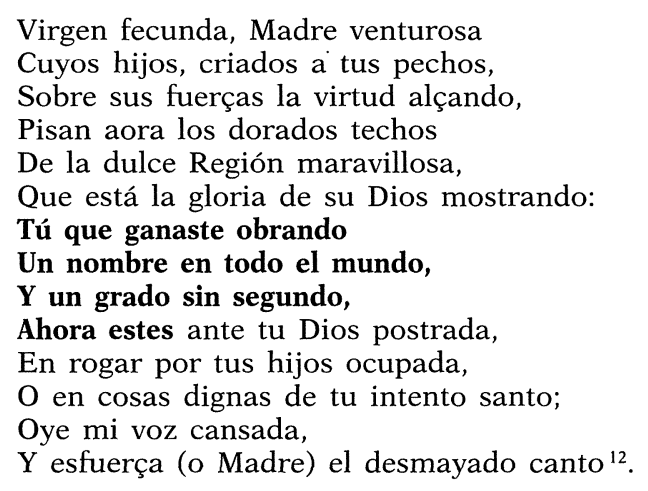

El agente inductor que más decisivamente contribuyó a la divinización, aquel que estimuló en mayor medida el ejercicio de contrafacción "a lo divino» en Cervantes, estribaba en una de las prescripciones formalmente establecidas en las bases de participación de la justa poética, en virtud de la cual se preceptuaba la composición de una canción more petrarquista que versara sobre los

12 Fray Diego de SAN José, Compendio de las solemnes fiestas que en toda España se hicieron en la Beatificación de N. B. M. Teresa de Jesús. Madrid, Por la viuda de Alonso Martín, fol. 52r. Los versos garcilasianos que Cervantes acomoda en esta estancia de su canción, van destacados en negrilla. 
éxtasis místicos de la Santa abulense, imponiendo indeclinablemente como paradigma imitable la Égloga I de Garcilaso:

Al que con más gracia, erudición, y elegante estilo, guardando el rigor
lírico, hiziere una canción castellana, en la medida de aquella de Garcilaso,
que comiença: «El dulce lamentar de los pastores»: A los divinos éxtasis
que tuvo nuestra Santa Madre, que no exceda de siete estancias, [... $]^{13}$.

Con esta exigencia imitativa, la actuación del glorioso escritor en tal evento queda, si no justificada, al menos explicada. Mas, pese a cuantas atenuantes quepa alegar, lo cierto es que la contradicción denunciada entre el dictamen y el proceder cervantinos respecto del ejercicio divinizador, no se resuelve del todo, y es, en sí misma, asaz sintomática de las magnas dimensiones que el fenómeno de la divinización literaria llegó a cobrar en la España aurisecular, incluyendo, dentro del alcance de su incontrastable influjo, aun a los más paladines detractores de la promiscuación sacroprofana.

6. Hora es ya de recapitular. Esta significativa cosecha permite, no obstante su parvedad, situar la personalidad de Cervantes en el encrespado clima de controversias que sobre la licitud de la práctica divinizadora se suscitó en el Siglo de Oro. En lo atañedero a la cuestión moral, la sensibilidad cervantina se mostraba reacia a la miscibilidad de la esfera profana con la sagrada; su espíritu propendía a distinguir nítida y escrupulosamente ambos ámbitos, desaprobando cualquier intento que procediera aleando los quilates religiosos con los seculares. En este punto, coincidía plenamente con el pensamiento de Baltasar Gracián, quien, en el aforismo núm. 251 de su Oráculo manual y arte de prudencia (1647), había declarado categóricamente que "hanse de procurar los medios humanos como si no hubiese divinos, y los divinos como si no hubiese humanos». De modo explícito manifestó Cervantes su oposición a la mixtura de valores sacros y profanos en el prólogo de la Primera Parte del Quijote (1605), consignando que «ni tiene [este vuestro libro] para qué predicar a ninguno, mezclando lo humano con lo divino, que es un género de mezcla de quien no se ha de revestir ningún cristiano entendimiento». Si Cervantes se alinea decididamente entre los corifeos detractores de tal uso literario, no menos es de destacar la nota diferencial que singulariza su modo de ejercer esta crítica, rara vez asentada en la censura abierta y directa; estribada, por el contrario, en la alusión velada y oblicua, aunque no por ello menos eficaz, que procede integrando en el organismo creativo de sus invenciones tales referencias a la actividad divinizadora, traspasándolas por un tamiz irónico. Caso aparte

13 Ob. cit., fol. $12 \mathrm{v}$. 
merece la disidencia perpetrada por Cervantes contra su credo estético, al incurrir, en su intervención en las justas poéticas en honor de la beatificación de Santa Teresa, en un procedimiento (el de la contrafacción poética "a lo divino») que figuraba en el elenco de las actuaciones divinizatorias que él mismo había impugnado en su conjunto. Esta antinomia entre teoría y práctica se revela como preciosa piedra de toque que sirve para aquilatar adecuadamente los límites a que se circunscribe la censura cervantina del ejercicio divinizador.

Francisco JAVIER SÁNCHEZ MARTíneZ 